\title{
TECNOLOGIA DA REALIDADE AUMENTADA NA PROPAGANDA: AVALIAÇÃO DA EFICÁCIA COM BASE EM ENTENDIMENTO, RISCO E RESPOSTA AFETIVA
}

\section{Ricardo Menzes Carvalho Pereira}

Mestre em Administração pela Universidade de Fortaleza - UNIFOR rpereira9ce@hotmail.com (Brasil)

\section{José Mauricio Galli Geleilate}

Mestre em Administração pela Universidade de Fortaleza - UNIFOR josemauriciogg@gmail.com (Brasil)

\section{Aurio Lucio Leocadio}

Doutorado em Administração pela Universidade de São Paulo - USP

Professor da Universidade Federal do Ceará - UFC

leocadio@unifor.br (Brasil)

\section{Danielle Miranda de Oliveira Arruda Gomes}

danielle@unifor.br (Brasil)

\section{RESUMO}

A Realidade Virtual, técnica que permite a interação entre pessoas e computadores, tem tido sua interface melhorada avançando para a tecnologia da Realidade Aumentada (RA), que permite uma interação "usuário-ambiente" mais eficiente e rica. Este estudo questiona como os consumidores avaliam a eficácia da propaganda em ambiente de Realidade Aumentada tendo como base o seu entendimento, a resposta afetiva e risco de compra. O uso da tecnologia da Realidade Aumentada foi avaliado neste estudo quanto à sua eficácia em propaganda via internet, no intuito de descobrir o quão eficazmente este recurso é percebido, com base nas influências dos constructos sobre percepção de risco do consumidor em relação ao produto, resposta afetiva ao experimentar o recurso e entendimento geral da propaganda. Utilizou-se como base teórica os conhecimentos a respeito dos usos da Realidade Aumentada, além do resgate de pesquisas que envolvessem os quatro pilares teóricos do estudo: risco percebido, entendimento, resposta afetiva e eficácia da propaganda. Foi realizada uma pesquisa de caráter exploratório, predominantemente quantitativa, com aplicação de questionários com 261 respondentes, abordados de forma não probabilística. Os resultados demonstraram que com o uso da tecnologia da Realidade Aumentada, o entendimento da propaganda apresenta uma relação positiva e significativa estatisticamente com eficácia da propaganda. Da mesma forma que a resposta afetiva também está positivamente relacionada com a essa eficácia. Entretanto, o risco percebido apresenta relação negativa com a eficácia, confirmando as hipóteses testadas pela pesquisa e a literatura existente.

Palavras chave: Inovação; Propaganda; Realidade Aumentada. 


\section{INTRODUÇÃO}

Com o crescente desenvolvimento da computação gráfica, Internet e seus navegadores, as representações do mundo real e da imaginação tornaram-se mais fáceis e interativas (ZHOU, 2008). Esses avanços tecnológicos permitiram o rompimento de barreiras, (com exemplo a tela do monitor) e passaram a gerar "ambientes tridimensionais interativos em tempo real por meio da realidade virtual". (TORI; KIRNER e SISCOUTTO, 2006).

Assim, a realidade virtual possibilitou a criação desses ambientes simulando a imersão de um indivíduo em mundos controlados por sistemas computadorizados, numa interface que transporta o usuário para ambiente artificial, simulado e tridimensional, onde o indivíduo visualiza e interage, em tempo real, com os objetos presentes, utilizando estímulos multi-sensoriais, como visão e audição (SANTOS FILHO, 2005).

Os avanços na multimídia, nas redes de computadores e nos dispositivos e equipamentos utilizados para processar a Realidade Virtual tornaram possível o seu desdobramento em uma interface melhorada e avançada, denominada de Realidade Aumentada (RA) (TORI, KIRNER E SISCOUTTO, 2006), que permite a interação "usuário-ambiente" mais eficiente, rica e natural (FILIPPO, ENDLER e FUKS, 2005).

A Realidade Aumentada, ainda em processo de desenvolvimento, começou a ser estudada na década de 60, mas somente a partir dos anos 90 que essa tecnologia tomou impulso (FERRARI, 2009). Sua aplicação pelos profissionais de propaganda e marketing pode modificar o processo de comunicação de produtos e marcas.

Portanto, este trabalho tem por objetivo geral analisar os efeitos do entendimento, do risco de compra e da resposta afetiva na eficácia do uso da tecnologia da Realidade Aumentada em propaganda via internet. Objetivou-se especificamente analisar: a relação entre o entendimento e a eficácia do uso da tecnologia da Realidade Aumentada na propaganda; a relação entre o risco percebido e a eficácia do uso da tecnologia da Realidade Aumentada na propaganda; e a relação entre a resposta afetiva do indivíduo e a eficácia do uso da tecnologia da Realidade Aumentada na propaganda.

Utilizou-se como base teórica os conhecimentos a respeito dos usos da Realidade Aumentada, juntamente com o resgate das pesquisas que envolvessem os quatro pilares teóricos do estudo: risco percebido, entendimento, resposta afetiva e eficácia de propaganda. Estes pilares foram escolhidos 
com base nas considerações de Pavlou e Stewart (2000) sobre a eficácia da propaganda via mídia interativa.

Para alcançar os objetivos propostos, foi realizada uma pesquisa de caráter exploratório, com aplicação de questionários com 261 respondentes, abordados de forma não probabilística. O preenchimento dos questionários ocorreu após a demonstração de uma propaganda com a utilização da tecnologia da Realidade Aumentada. Foram utilizadas técnicas de estatística descritiva na análise de dados, alem de técnicas multivariadas de dados: análise fatorial confirmatória e o uso de modelagem de equações estruturais na verificação do modelo e nos testes de hipóteses.

A metodologia do trabalho vem em seguida, descrevendo o tipo de pesquisa e apresentando a forma como foi constituída a análise dos dados. Finalmente a análise de resultados apresenta as principais descobertas do trabalho bem como responde ao objetivo geral desta pesquisa, seguido das conclusões.

Com o fornecimento de novas informações a respeito das reações dos consumidores diante da Realidade Aumentada, este trabalho procura desenvolver o campo teórico e empírico ao apontar as características mais marcantes que a Realidade Aumentada proporciona em ações de publicidade e propaganda bem como sua pertinente eficácia.

\section{REALIDADE AUMENTADA}

Realidade Aumentada - RA é a mistura de mundos reais e virtuais em algum ponto da realidade/virtualidade contínua, que conecta ambientes completamente reais a ambientes completamente virtuais (MILGRAN, 1994, apud KIRNER; SISCOUTTO, 2007).

Um sistema de Realidade Aumentada gera uma visão composta para o usuário que é a combinação da cena real e uma cena virtual gerada por computador, ampliada com informações adicionais e projetada para melhorar a percepção sensorial do usuário. O objetivo da Realidade Aumentada é criar um sistema no qual o usuário não percebe a diferença entre o mundo real e o virtual. Seu princípio é simples, o usuário precisa ter uma câmera instalada em seu computador, capaz de reconhecer códigos impressos em figuras que, por sua vez, aciona um programa criando personagens virtuais. Para que essa interação aconteça é necessária a utilização de um software que tenha capacidade de observar o ambiente real, analisando os dados e extraindo de alguma forma informações sobre a localização, orientação e interações sobre os objetos virtuais (AZUMA, 2001).

Revista de Administração e Inovação, São Paulo, v. 10, n.3, p.09-36, jul./set. 2013. 
O software utilizado na Realidade Aumentada, denominado de ARToolKIT, tem a capacidade de observar o ambiente real, analisar e extrair os dados desse ambiente e processar informações sobre localização, orientação e interações dos objetos virtuais no intuito de permitir ao usuário a visualização, em ambiente real, desses objetos sobrepostos. (SANTOS FILHO, 2005). Inicialmente desenvolvido na Universidade de Osaka, no Japão, e apoiado pela Universidade de Canterbury, na Nova Zelândia, e pelo Human Interface Technology Laboratory da Universidade de Washington, nos Estados Unidos, o ARToolKit é um software de apoio à tecnologia e aos dispositivos especiais para o “desenvolvimento rápido de aplicações de Realidade Aumentada” (FILIPPO, ENDLER; FUKS, 2005).

O ARToolKit caracteriza-se por ser uma biblioteca gráfica que fornece resultados de rastreamento em três dimensões e em tempo real, com baixo custo operacional. É de distribuição livre, sem fins comerciais, com código aberto para realização de "modificações pelos usuários, de acordo com as suas necessidades" (SISCOUTTO; COSTA, 2008).

Para que a Realidade Aumentada funcione, o usuário precisar posicionar uma imagem predefinida (códigos impressos ou marcadores), bem de frente a uma câmera acoplada a um computador. A câmera reconhece a figura projetando um objeto 3D ou uma animação na tela do computador. Ao processar o reconhecimento dos códigos impressos/marcadores, o programa faz uso de técnicas de visão computacional para rastrear e calcular, em tempo real, a sua posição de referência em relação ao dispositivo de captura de vídeo. Assim, os objetos virtuais tridimensionais devidamente cadastrados podem ser sobrepostos e alinhados sobre estes marcadores no ambiente real (SISCOUTTO; COSTA, 2008).

Após a imagem de vídeo ser capturada pela webcam o ARToolKit a converte em imagem binária, ou seja, em preto e branco. Em seguida, essa imagem é analisada pelo software, no intuito de detectar o marcador existente, constituído por uma forma geométrica quadrada de cor escura desenhada no papel. Para o reconhecimento do marcador, utiliza-se moldura em branco externa envolvendo esse quadrado escuro para promover o contraste no próprio marcador, (SANTOS FILHO, 2005) conforme mostrado na Figura 1. 

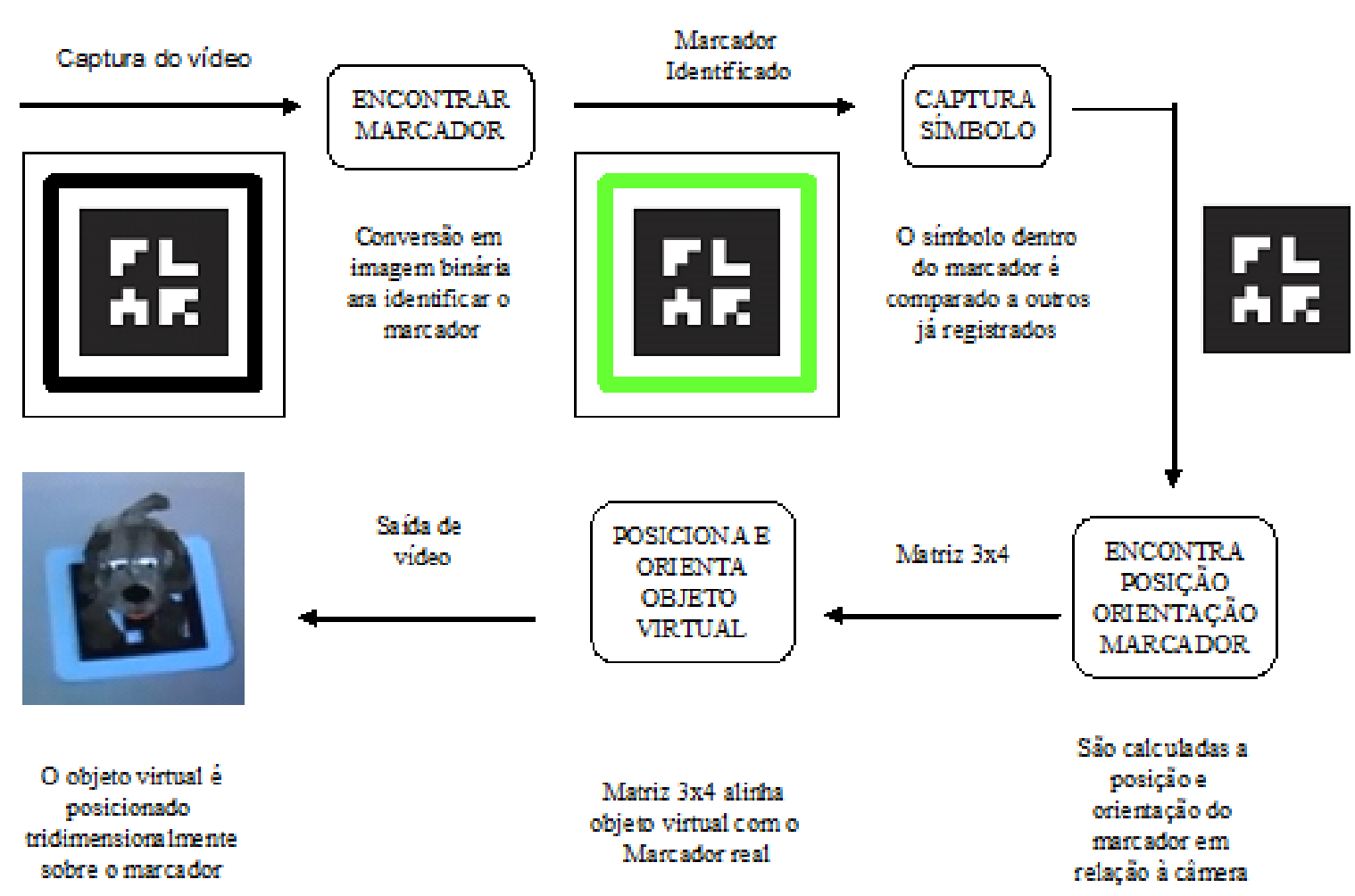
Matriz 3x4 alima obje to virtual com o Marcador real
Sâo calculadas a
posiçãoe
crientaçảo do
marcador em
relaçẩo à câmera

Figura 1 - Diagrama de funcionamento do ARToolKit. Fonte: Adaptado de Siscoutto e Costa (2008, p. 187).

A Realidade Aumentada proporciona ao usuário interação segura e agradável, eliminando em grande parte a necessidade de treinamento, pelo fato de trazer para o ambiente real os elementos virtuais, enriquecendo e ampliando a visão que ele tem do mundo real. Para que isso se torne possível, é necessário combinar técnicas de visão computacional, computação gráfica e realidade virtual, o que gera como resultado a correta sobreposição de objetos virtuais no ambiente real. (AZUMA 1993). Uma vez disponível no mercado, sistemas de Realidade Aumentada irão mudar a forma como as pessoas irão ver o ambiente. Existe uma gama de possibilidades na utilização desta nova tecnologia, tais como na divulgação de vídeos clipes, filmes, eventos musicais, lançamentos de imóveis etc.

A Realidade Aumentada pode ser também utilizada na educação, para melhor entendimento do aluno sobre a formação de nuvens, a estrutura do universo, da galáxia etc. Em jogos de entretenimento, principalmente no desenvolvimento de novas aplicações ou na remodelagem de aplicações já existentes usando comportamentos e cenários mais realistas fornecendo aos usuários ambientes reais e interativos. Novas tecnologias estão sendo pesquisadas no campo da RA com o intuito de melhorar os aspectos dos projetos de arquitetura, construção e manutenção. A realidade virtual pode ser utilizada 
para visualizar paisagens modificadas, e para avaliar o impacto das construções propostas (NOVITSKI, 1994).

Na medicina, a RA permitirá que cirurgiões possam a ter melhor percepção sensorial do corpo do paciente durante uma operação. Isso resultará em menos risco e mais eficiência nas intervenções cirúrgicas. Sendo útil também para fins de treinamentos médicos. (KANCHERLA, 1995). Instruções virtuais podem lembrar um cirurgião principiante dos passos necessários, sem a necessidade de desviar o olhar de um paciente e consultar um manual (DURLACH, 1995). Enfim, são muitas as aplicações e contribuições da RA para a sociedade.

Empresas brasileiras estão utilizando a Realidade Aumentada em cases de marketing e propaganda, embora de forma embrionária e tímida. Internacionalmente já existem várias campanhas publicitárias que já estão utilizando a tecnologia para criar diferenciais de interação com o público. Segundo o publicitário Ohmar Tacla (2009), a demanda por trabalhos publicitários em Realidade Aumentada vem evoluindo de forma espantosa, sendo essa área a responsável em levar esta tecnologia ao grande público brasileiro. A Coca-Cola, com o refrigerante Fanta, a Skol, com sua cerveja, a Chevrolet, com o Vectra, a Ford, com o novo Ford Ka são exemplos de campanhas publicitárias que migraram para essa nova tecnologia. A PepsiCo colocou nas embalagens de uma edição especial de seus Doritos Sweet Chili a RA. Cada pacote traz no verso um símbolo, que ao ser ativado no site da marca libera monstrinhos em 3D chamados Doritos Lover, resultando em mais de 200 mil combinações diferentes de monstrinhos. Já a Lego montou em um ponto de venda uma estrutura sob a qual as crianças colocam a caixa do brinquedo e, na tela, aparece ele montado. Muito mais que descobrir qual a figura, a tecnologia cria interatividade, fazendo com que a marca ganhe destaque (MERIGO, 2009).

\section{O MODELO TEÓRICO DO ESTUDO}

O uso de novas tecnologias no intuito de promover as vendas é um fator determinante de diferenciação entre as empresas. Neste contexto, o avanço de inovações tecnológicas aplicadas a 
pesquisas realizadas em pontos de venda merece destaque (SIMINSON; CARMON; DHAR; DROLET; NOWLIS, 2001).

Cutler (1990) define o conceito de mídia interativa como uma mídia capaz de prover uma propaganda instantânea que ao mesmo tempo execute a venda e colete o pagamento. Com o advento da internet e outras tecnologias, as interações entre as organizações e os clientes estão se tornando cada vez mais próximas. $\mathrm{O}$ uso da internet e outros tipos mídia interativa demonstram ser mais eficazes, customizáveis, flexíveis e mais responsivas do que a mídia comum (PORT 1999; NOVAK; HOFFMAN 1996).

Em geral, os principais objetivos da propaganda por meio de mídia interativa tendem a ser similares aos objetivos da propaganda tradicional (PAVLOU; STEWART, 2000). Isto significa, primeiramente, que as mensurações já utilizadas na propaganda tradicional podem ser replicadas para a propaganda interativa. No entanto, a propaganda interativa tem o potencial de melhorar a eficácia dos anúncios e a qualidade da decisão dos consumidores, aumentando a satisfação e o envolvimento destes com o produto, promovendo também relações de confiança por meio de troca de informações, assistência técnica e redução de informações assimétricas entre o consumidor e a empresa (PAVLOU; STEWART, 2000).

Estudos realizados sobre o tema de eficácia da propaganda indicam que o gostar de um anúncio (likability) contribui para sua eficácia (EWING; NAPOLI; DU PLESSIS, 1999), chegando a considerá-lo como o melhor prognóstico de sucesso da propaganda (HALEY; BALDINGER, 1991). Pondera-se, também, que as propagandas com alto grau de likability estão associadas com a persuasão (GREENE, 1992; MURPHY; TANG, 1998). Nesta linha, Biel e Bridgwater (1990) verificaram empiricamente que pessoas que gostam muito de comerciais têm o dobro de probabilidade de serem persuadidas por eles do que pessoas que se sentem neutras em relação aos mesmos. Inferindo as causas para tal comportamento, os autores afirmam que "a propaganda apreciada impacta na persuasão, pois um comercial apreciado afeta o componente emocional das atitudes em relação à marca" (BIEL; BRIDGWATER, 1990).

Conforme as considerações de Blackwell, Miniard e Engel (2005) sobre o comportamento de compra, as atitudes e intenções de consumo constituem bons indicadores para a determinação da eficácia da propaganda. Portanto, este estudo enfocou a análise dos efeitos do entendimento, do risco de compra e da resposta afetiva com a eficácia do uso da tecnologia da Realidade Aumentada na propaganda via internet. $\mathrm{O}$ modelo concebido para nortear esta pesquisa fundamentou-se em quatro constructos: risco de compra; resposta afetiva; entendimento e eficácia da propaganda.

Revista de Administração e Inovação, São Paulo, v. 10, n.3, p.09-36, jul./set. 2013. 


\subsection{Entendimento}

A terceira dimensão do modelo fundamentou-se em McQuarrie e Mick (1999), cuja pesquisa enfocou a entendimento da propaganda, abordando facilidade de entendimento, clareza dos significados e objetividade da mensagem. Estes autores construíram uma escala de diferencial semântico composta por três itens objetivando medir o grau de dificuldade que as pessoas têm para compreender o significado da propaganda.

Sheth, Mittal e Newman (2001) definem o comportamento do cliente de bens de consumo como as atividades físicas e mentais realizadas que resultam em decisões e ações, que por sua vez caracterizam atitudes de avaliação pessoal, que podem ser positivas ou negativas. As atitudes positivas em relação a um objeto tendem a comportamentos de aproximação. Atitudes negativas possivelmente se engajam em comportamentos de rejeição.

Engel, Blackwell e Miniard (1995) afirmam que as atitudes dos consumidores são frequentemente utilizadas para julgar a eficácia das atividades de marketing [...] ajudar na avaliação das ações de marketing mesmo antes que elas sejam implementadas no mercado [...] podendo ser usadas para segmentar mercados e escolher segmentos-alvo.

\subsection{Risco de compra}

Para Solomon (1998) o risco percebido implica sempre desconfiança de que a aquisição de determinado produto ou serviço venha a ter consequências negativas. Já Sitkin e Pablo, (1992) consideram que o risco percebido pode acarretar também decisões nas quais exista a incerteza sobre as conseqüências significantes que possam acontecer. Para estes autores o risco abrange tanto resultado positivo como negativo, não sendo o resultado em si que constitui o risco, mas o grau de frustração que ele carrega.

Quanto ao uso do constructo para pesquisa, amparou-se em Dean (2003), que desenvolveu uma escala baseada em estudos de Fornell e Larcker (1981) e Dean e Biswas (2001), que abordaram a avaliação do erro e a avaliação dos produtos antes compra. O instrumento construído por Dean (2003) é composto por quatro afirmativas com intuito de medir, por meio de escala do tipo Likert de sete

Revista de Administração e Inovação, São Paulo, v. 10, n.3, p.09-36, jul./set. 2013. 
pontos, o grau de risco atribuído pelo consumidor à compra de um produto apresentado em um anúncio ao qual foi exposto.

\subsection{Resposta Afetiva}

Quanto à resposta afetiva ao anúncio, o estudo foi embasado em Bhat, Leigh e Wardlow (1998). Os autores conduziram uma pesquisa que consistiu em uma exposição de estudantes a propagandas com conseqüente descrição das emoções experimentadas. A partir deste trabalho, elaboraram uma escala de diferencial semântico, com nove frases medindo a reação das pessoas às propagandas às quais foram expostas, com ênfase em sentimentos dos tipos positivos e/ou agradáveis.

Um conjunto de estudos mostra que as respostas afetivas são importantes para a efetivação da compra e se relacionam fortemente com outros estados pós-consumo, por exemplo, satisfação (HAVLENA e HOLBROOK, 1986; MANO e OLIVER 1993; RICHINS, 1997).

De acordo com Westbrook e Oliver (1991), as respostas afetivas podem ser definidas como as emoções emergidas em uma experiência de consumo. Estas emoções permite determinar o afeto, o estado de humor e o sentimento do consumidor (BATRA e RAY, 1986) em relação a uma propaganda, fatores importantes para compreender como pensam, julgam, avaliam e decidem o consumidor em uma ação de compra (WESTBROOK e OLIVER, 1991).

\subsection{Eficácia}

Por fim, O construto eficácia da propaganda foi incluído no modelo ancorado em Moreau, Markman e Lehman (2001), que desenvolveram uma escala com o intuito de avaliar uma propaganda, com ênfase nas dimensões informativa e influenciadora do anúncio. Segundo Fishbein et al. (2002 apud GRENCHO, 2010) uma propaganda apresenta relação muito próxima com o comportamento desejado e do publico alvo. Sua eficácia depende de seu conteúdo, que deve carregar sempre elementos de novidade (GRENCHO, 2010). Para Beleli (2007) uma propaganda eficaz oferece ao consumidor a sensação de que a ele está sendo dada a liberdade de escolha de um produto ou serviço de acordo com o seu modo de ser

Assim, o modelo utilizado neste trabalho foi delineado conforme apresentado na figura 2, considerando que a eficácia da propaganda deve sofrer impactos positivos do entendimento, da resposta afetiva e o risco negativo.

Revista de Administração e Inovação, São Paulo, v. 10, n.3, p.09-36, jul./set. 2013. 


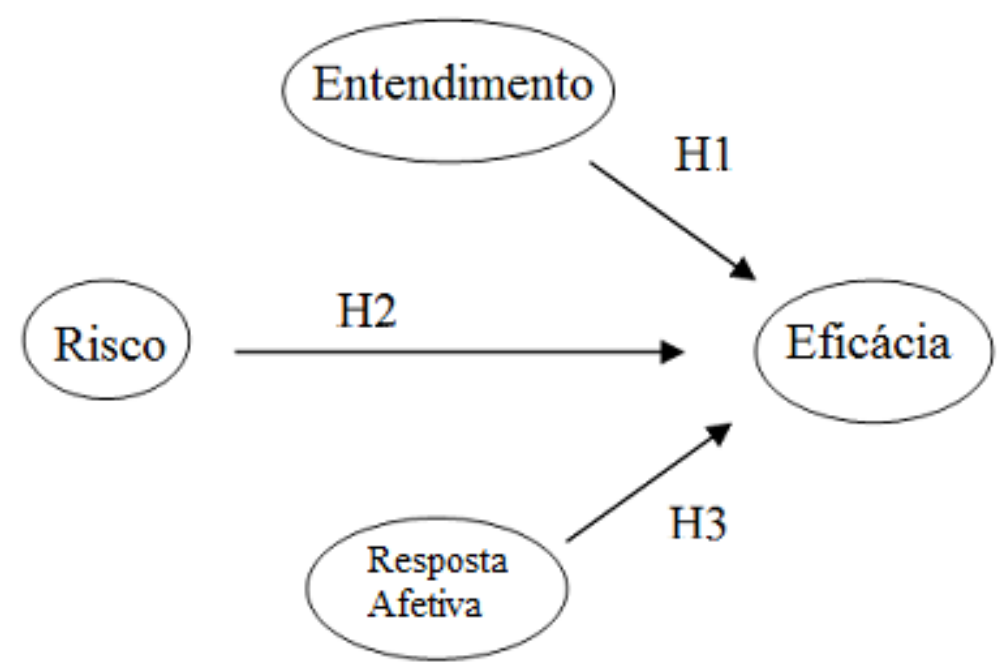

Figura 2. Modelo Teórico Proposto.

Fonte: Elaborado pelos autores (2010)

As hipóteses do estudo foram, então, estabelecidas:

Hipótese H1: O entendimento que o indivíduo obteve da propaganda exerce influência positiva na avaliação da eficácia da propaganda com Realidade Aumentada.

Hipótese H2: O risco percebido na propaganda exerce influência negativa na avaliação da eficácia da propaganda com Realidade Aumentada.

Hipótese H3: A resposta afetiva do indivíduo durante a propaganda exerce influência positiva na avaliação da eficácia da propaganda com Realidade Aumentada.

A primeira hipótese amparou-se em Pavlou e Stewart (2000), cujos estudos estabeleceram a relevância da característica "clareza" na comunicação entre empresa e cliente por meio da mídia interativa, desta forma tornou-se importante investigar se este tipo de mídia interfere no entendimento do consumidor sobre a propaganda.

A segunda hipótese baseou-se em Nelson (1970), para quem a busca, por parte do consumidor, de informações sobre produtos tem custos que incluem tempo, deslocamentos para visitar lojas, examinar produtos, ler propagandas e conversar sobre a experiência de outros consumidores. Nesta busca, os consumidores são particularmente atraídos por informações que sejam eficientes em significado (JACOBY; SZYBILLO; BUSATO SCHACH, 1977). Pavlou e Stewart (2000) estabeleceram, ainda, que a propaganda interativa aumenta o potencial de compra ao facilitar a 
aquisição do produto. A experiência com a Realidade Aumentada pode, então, reduzir os riscos e ser percebida pelos consumidores como um guia eficiente da qualidade do produto.

A terceira hipótese extraiu-se das conclusões de Martindable (1981) e Denis (2001), que consideraram que os estímulos físicos ou de informações sensoriais captadas pelos órgãos dos sentidos formam a percepção, que é um pré-requisito para a formação dos conceitos ou representações dos objetos e, conseqüentemente coordenam o sistema de ação, o que permite estabelecer que as sensações percebidas pela utilização da tecnologia de Realidade Aumentada devem ser determinantes na eficácia da propaganda.

\section{METODOLOGIA}

Este estudo, de natureza quantitativa, foi conduzido por meio da utilização de técnicas multivariadas, notadamente modelagem de equações estruturais (Hair, 2005). Pode ser classificado, conforme Yin (2007), como um estudo exploratório, uma vez que observou-se escassez de pesquisas abordando esta temática. Ademais, este estudo foi precedido por uma pesquisa bibliográfica realizada por meio da técnica "desk research", onde fontes secundárias foram pesquisadas (trabalhos técnicos e propagandas utilizando a Realidade Aumentada), seguindo as recomendações de Malhotra (2006). Os dados primários foram obtidos por meio de questionário estruturado aplicados em uma população de jovens estudantes universitários, caracterizando esta pesquisa como do tipo survey. Os dados foram coletados dentro do campus de uma universidade, obtendo-se um total de 261 respondentes. O delineamento da população foi realizado com o intuito de obter uma quantidade significativa de respondentes para o trato estatístico tendo por base a limitação proposta pela técnica multivariada, que permite analisar simultaneamente múltiplas medidas em cada indivíduo ou objeto sob investigação com o propósito de explicar e predizer o grau de relação entre as variáveis observadas. Adotou-se uma concepção de estudo transversal, pois os dados quantitativos foram coletados somente uma vez (MALHOTRA, 2006) durante os meses de janeiro e de fevereiro do ano de 2010.

$\mathrm{Na}$ elaboração do questionário do presente estudo, foram utilizadas quatro modalidades de escalas de Marketing, todas adaptadas do trabalho de compilação de escalas para medir o comportamento do consumidor e a sua atitude frente a propagandas, realizado por Bruner, Hensel e James (2005). As informações coletadas por meio dessas escalas de Marketing foram apoiadas em escala de Likert (1932) de onze pontos, justamente para verificar a intensidade da atitude dos 
entrevistados frente às afirmações do questionário. Assim, as perguntas formuladas foram divididas por abordagem de assunto em quatro grupos distintos.

O primeiro grupo de questões foi composto por nove frases de diferencial semântico, com o objetivo de mensurar a reação de uma pessoa exposta a um anúncio, enfatizando-se os tipos de sentimentos positivos e/ou agradáveis experimentados por essa pessoa.

No segundo, procurou-se avaliar a entendimento do entrevistado em relação à propaganda do produto promovida pela experimentação virtual de óculos, considerando se o entendimento foi fácil ou difícil, se a propaganda teve abordagem direta ou confusa e se o significado transmitido com a propaganda foi claro ou ambíguo. Para tanto, adotou-se a Escala de Atitude no tocante à Propaganda, composta por três itens de diferencial semântico destinados a mensurar a dificuldade que uma pessoa tem para entender o significado da propaganda.

O terceiro grupo foi elaborado com sete questões sobre a eficácia da propaganda e aborda o quanto à propaganda foi informativa e o quanto ela influenciou o entrevistado. O quarto grupo constou de quatro questões sobre a percepção de risco do produto, buscando verificar se um consumidor acredita que a compra do produto anunciado pode ser considerada arriscada, avaliando a desvantagem de comprar um produto da Ray Ban se este fosse adquirido por meio da página eletrônica da empresa e não em loja física, considerando que o consumidor teria como única referência à experimentação virtual do produto.

A pesquisa utilizou o programa Ray Ban Virtual Mirror, disponível para download no site www.ray-ban.com, da empresa Ray Ban que confecciona óculos de sol. Com esse programa o usuário tem a oportunidade de ter experiência com a Realidade Aumentada sem precisar fazer a impressão do código para colocar em frente a webcam, pois o programa faz o reconhecimento facial do usuário, permitindo a interação, pela Realidade Aumentada, entre máquina e usuário.

Inicialmente foi realizado pré-teste com 40 universitários de graduação de uma Universidade da cidade de Fortaleza, para identificar problemas de preenchimento e entendimento do questionário, os quais não participaram da composição da amostragem final. A demonstração foi realizada em uma sala de aula, utilizando-se um notebook com o software Virtual Mirror e acoplado a um projetor multimídia. Um aluno foi escolhido para servir de usuário, que ao colocar seu rosto em frente a webcam do computador, como um espelho, tinha sua face reconhecida pelo aplicativo, com a projeção de sua imagem na tela do notebook. $\mathrm{O}$ restante dos universitários acompanhou a demonstração pela imagem do projeto multimídia da 
sala de aula. A partir de então, o usuário tinha a sua disposição vários modelos de óculos, e com um gesto em direção aos óculos escolhido, este imediatamente aparecia na imagem de seu rosto, projetada na tela do computador. Os óculos podem ser visto de diferentes ângulos, basta que o usuário movimente a cabeça de um lado para o outro. O programa possibilita ainda, a customização do produto escolhido pela alteração de suas cores. O aplicativo permite que o consumidor faça a compra via Internet ou então anote o código do modelo dos óculos para comprá-lo diretamente na loja, evitandose, assim, desperdício de tempo durante a escolha do modelo no ponto de venda. Após cada apresentação, foram aplicados questionários entre o grupo amostral, que foram preenchidos na presença do pesquisador de forma escrita.

Tendo por objetivo a integração dos construtos do estudo e analise de suas relações, utilizou-se a Modelagem de Equações Estruturais (SEM), uma vez que ser trata de uma técnica que combina aspectos na regressão múltipla, com a análise fatorial (HAIR et al., 2005). A elaboração do modelo seguiu uma abordagem exploratória, que é reconhecida por Jöreskog e Sörbom (1993) como abordagem de geração de modelos. A Modelagem de Equações Estruturais pode ser utilizada para propósitos confirmatórios e para projetos exploratórios (ANDERSON; GERBING, 1988; KLINE, 1998). Segundo Anderson e Gerbing (1988), o limite entre as abordagens exploratórias e confirmatórias não é claro, uma vez que a maioria dos modelos utilizados em análise confirmatória não são ajustados imediatamente. Nesses casos estes modelos não são descartados, sendo sugeridas modificações que caracterizam a investigação como de caráter exploratório.

No intuito de avaliar o modelo teórico proposto, foi utilizado o software SmartPLS 2.0, capaz de modelar as equações estruturais inerentes ao constructo. A análise dos dados também foi efetuada como o auxílio do software estatístico SPSS (Statistical Package for Social Science, versão 15.0) para análise das técnicas multivariadas. Outra técnica utilizada na verificação deste modelo foi a de Bootstrapping, que consiste na repetição de amostragens originais, para efeito de comparação dos resultados com o que foi obtido na amostra utilizada. Desta forma, obteve-se o teste $\mathrm{T}$, que serviu de parâmetro para confirmação das hipóteses do estudo.

\section{ANÁLISE DOS RESULTADOS}

No intuito de analisar os padrões de respostas e formato das distribuições, a média, o desvio padrão e a curtose dos itens pesquisados foram calculados (Tabela 1) para os constructos "resposta 
afetiva" (questões 1 a 9) "entendimento" (questões 10 a 12), "eficácia"(questões 11 a 19) e "risco" (questões 20 a 23).

\begin{tabular}{|c|c|c|c|c|c|c|c|}
\hline Item & Média & Desvio $P$. & Curtose & Item & Média & Desvio $P$. & Curtose \\
\hline 1-Estimulado & 8,34 & 1,42 &, 120 & 13-Eficácia & 8,51 & 1,51 & 7,775 \\
\hline 2-Interessado & 8,24 & 1,60 & 4,622 & $\begin{array}{l}\text { 14-Avaliação global } \\
\text { da propaganda }\end{array}$ & 8,68 & 1,48 & 8,819 \\
\hline 3-Envolvido & 8,08 & 1,84 & 4,565 & 15-Aprendizado & 6,65 & 3,08 &,- 860 \\
\hline 4-Feliz & 7,91 & 1,84 & 4,811 & 16-Entendimento & 7,17 & 2,82 & ,232 \\
\hline 5-Inveja & 5,52 & 3,23 &,- 941 & $\begin{array}{l}\text { 17-Dúvida sobre } \\
\text { Características do } \\
\text { produto }\end{array}$ & 2,88 & 2,64 &, 574 \\
\hline 6-Curioso & 8,59 & 1,31 &, 018 & $\begin{array}{l}\text { 18- Propaganda } \\
\text { Realista }\end{array}$ & 7,65 & 2,33 & 1,866 \\
\hline 7-Agradável & 8,50 & 1,46 & 9,685 & 19-Intenção de comp. & 8,29 & 1,70 & 3,823 \\
\hline 8-Animador & 8,57 & 1,36 & 6,242 & $\begin{array}{c}\text { 20-Produto é escolha } \\
\text { errada }\end{array}$ & 2,16 & 1,87 & 1,998 \\
\hline 9-Desejo & 8,16 & 1,82 & 3,172 & 21-Compra Arriscada & 2,59 & 2,12 & 1,419 \\
\hline $\begin{array}{c}10- \\
\text { Entendimento }\end{array}$ & 8,74 & 2,14 & 6,173 & $\begin{array}{c}\text { 22-Insatisfação da } \\
\text { compra }\end{array}$ & 2,81 & 2,32 &, 795 \\
\hline 11-Direta & 8,90 & 1,73 & 6,857 & \multirow{2}{*}{$\begin{array}{l}\text { 23-Produto não } \\
\text { atenderia expectativas }\end{array}$} & 2,95 & 2,47 & ,817 \\
\hline 12-Clareza & 8,97 & 1,70 & 10,150 & & & & \\
\hline
\end{tabular}

Tabela 1. Média, desvio padrão e curtose dos padrões de resposta e formato das distribuições dos itens pesquisados.

Fonte: Elaborado pelos autores (2010)

Percebe-se, pela Tabela 1, média elevada (acima de 8,0) de resposta para a maioria das perguntas feitas, indicando boa avaliação para a resposta afetiva, entendimento e eficácia da propaganda. A questão cinco, que aborda sobre o sentimento de inveja no momento da experiência com a RA, apresentou média menor de avaliação. Isto ocorreu, provavelmente, pela falta de pertinência deste sentimento com o momento da pesquisa e, talvez, falta de entendimento pleno por parte do entrevistado a respeito do que realmente a pergunta pretendia descobrir. As questões quinze, que aborda o fato de a propaganda ter melhorado o aprendizado sobre o produto, e dezesseis, sobre o entendimento do produto, também apresentaram avaliação um pouco baixa. Isto pode ser relacionado ao fato de a propaganda ter sido feita sobre óculos de sol, onde provavelmente os respondentes não perceberam melhor aprendizado ou melhor entendimento sobre a utilização deste item uma vez que é de simples uso. Segundo Solomon (2002) o conhecimento existente sobre um produto pode ser resultado de uma aprendizagem que tenha ocorrido em ocasiões anteriores, quando já se tinha procurado informações relevantes ou experimentado uma ou mais alternativas. As informações 
também podem ser obtidas de maneira passiva, mediante a exposição dos consumidores às propagandas, às embalagens e às atividades promocionais de venda.

A questão dezessete sobre características apresentou média baixa por questionar se o entrevistado encontrava dúvidas sobre as características do produto, indicando que realmente a propaganda foi clara em sua apresentação. As questões sobre percepção de risco (questões 20, 21,22 e 23) apresentaram também médias baixas, indicativo de baixa percepção de risco avaliada para o produto.

A Tabela 2 apresenta os valores percentuais das notas atribuídas pelos entrevistados para as questões sobre Resposta Afetiva. Observa-se que as médias citadas anteriormente foram elevadas por causa da forte concentração dos resultados, onde em média $72,15 \%$ da população atribuiu notas de 8 a 10. Destacam-se anotações para agradabilidade e animação onde $85,4 \%$ dos entrevistados deram notas de 8 a 10. A curiosidade em relação à Realidade Aumentada também foi muito elevada onde cerca de $30 \%$ de todos os respondentes lhe atribuíram nota máxima.

\begin{tabular}{|c|c|c|c|c|c|c|c|c|c|c|c|c|}
\hline Variáveis & $\mathbf{0}$ & $\mathbf{1}$ & $\mathbf{2}$ & $\mathbf{3}$ & $\mathbf{4}$ & $\mathbf{5}$ & $\mathbf{6}$ & $\mathbf{7}$ & $\mathbf{8}$ & $\mathbf{9}$ & $\mathbf{1 0}$ & \\
\hline Muito Estimulado & - & - & - & 0,4 & & 3,8 & 7,3 & 12,6 & 27,2 & 22,6 & 26,1 & 100 \\
\hline Muito Interessado & 0,4 & 0,8 & - & - & 1,1 & 1,9 & 7,3 & 14,6 & 25,7 & 24,1 & 24,1 & 100 \\
\hline Muito Envolvido & 1,5 & - & 0,4 & - & 1,9 & 5,4 & 5,4 & 13 & 23,8 & 27,2 & 21,5 & 100 \\
\hline Muito Feliz & 1,5 & 0,8 & & 0,4 & 0,4 & 5,4 & 8 & 15,7 & 24,1 & 26,4 & 16,9 & 100 \\
\hline Muita Inveja & 15,7 & 3,8 & 3,1 & 3,1 & 3,1 & 14,2 & 10,7 & 12,3 & 14,9 & 11,5 & 7.7 & 100 \\
\hline Muita Curiosidade & - & - & - & - & - & 2,7 & 5,7 & 11,5 & 19.5 & 30,7 & 29,9 & 100 \\
\hline Muito Agradável & 0,8 & - & 0,4 & 0,4 & 0,4 & 1,5 & 2,3 & 8,8 & 29,5 & 31,8 & 24,1 & 100 \\
\hline Muito Animador & 0,4 & - & - & - & 0,8 & 2,7 & 2,7 & 8 & 27,2 & 31,4 & 26,8 & 100 \\
\hline Muito Desejo & 0,8 & - & 0,4 & 1,9 & 1,1 & 5,7 & 5,4 & 10 & 19,9 & 33 & 21,8 & 100 \\
\hline
\end{tabular}

Tabela 2. Resposta afetiva em relação ao produto ao assistir a propaganda da Ray Ban. Fonte: Elaborado pelos autores (2010)

Com relação ao entendimento da propaganda observa-se na Tabela 3 uma concentração de notas entre os parâmetros 8 e 10, superior as notas atribuídas para resposta afetiva. Em média, 88,3\% da população atribuiu notas de 8 a 10 ao entendimento da propaganda, destacando, assim, a clareza e objetividade da propaganda via Realidade Aumentada.

\begin{tabular}{|c|c|c|c|c|c|c|c|c|c|c|c|c|}
\hline Variáveis/ Grau & $\mathbf{0}$ & $\mathbf{1}$ & $\mathbf{2}$ & $\mathbf{3}$ & $\mathbf{4}$ & $\mathbf{5}$ & $\mathbf{6}$ & $\mathbf{7}$ & $\mathbf{8}$ & $\mathbf{9}$ & $\mathbf{1 0}$ & $\mathbf{\%}$ \\
\hline Entendimento & 1,5 & 1,1 & 1,9 &, 8 & 1,5 & 1,1 & 1,9 & 3,1 & 11,1 & 5,3 & 0,6 & 00,0 \\
\hline Direta &, 4 &, 4 & 1,1 &, 4 & 1,5 & 2,7 & 1,9 & 4,2 & 10,3 & 7,2 & 9,8 & 00,0 \\
\hline Clareza &, 8 &, 8 &, 4 &, 4 & 1,1 & 1,5 & 2,3 & 2,3 & 11,9 & 7,6 & 1,0 & 00,0 \\
\hline
\end{tabular}

Tabela 3 Entendimento em relação à propaganda.

Fonte: Elaborado pelos autores (2010) 
No constructo eficácia da propaganda, em média $70,8 \%$ da população entrevistada atribuiu notas de 8 a 10, indicando que a propaganda via Realidade Aumentada é bastante eficaz, onde 82,4\% dos respondentes dera nota de 8 a 10 para a questão sobre a eficácia da propaganda e 84,3\% dos respondentes avaliaram globalmente a propaganda com notas entre 8 e 10. A exceção foi a questão sobre dúvidas em relação ao produto, que obteve $58,2 \%$ das notas entre 0 e 2 , o que indica o fato da propaganda ter gerado poucas dúvidas sobre o produto, Tabela 4. Importante ressaltar também a frequência de $79 \%$ dos entrevistados atribuíram uma alta intenção de compra do produto (notas entre 8 a 10).

\begin{tabular}{|c|c|c|c|c|c|c|c|c|c|c|c|c|}
\hline Variáveis/ Grau & $\mathbf{0}$ & $\mathbf{1}$ & $\mathbf{2}$ & $\mathbf{3}$ & $\mathbf{4}$ & $\mathbf{5}$ & $\mathbf{6}$ & $\mathbf{7}$ & $\mathbf{8}$ & $\mathbf{9}$ & $\mathbf{1 0}$ & $\%$ \\
\hline 13-Eficácia & 0,8 & - & 0,4 & 0,3 & 0,4 & 2,3 & 4,2 & 9,6 & 22,6 & 33,0 & 26,8 & 100 \\
\hline 14-Avaliação global da propaganda & 0,8 & - & - & 0,4 & 0,4 & 2,3 & 2,3 & 9,6 & 17,2 & 34,9 & 32,2 & 100 \\
\hline 15-Aprendizado & 3,4 & 4,2 & 7,3 & 5,4 & 6,9 & 6,1 & 6,9 & 7,3 & 14,2 & 16,5 & 21,8 & 100 \\
\hline 16-Entendimento & 3,4 & 3,4 & 5,0 & 1,9 & 3,8 & 6,1 & 5,7 & 8,8 & 16,9 & 26,8 & 18,0 & 100 \\
\hline 17-Dúvida sobre Características do produto & 18,0 & 14,6 & 25,7 & 13,4 & 6,5 & 6,1 & 3,1 & 3,4 & 3,1 & 3,1 & 3,1 & 100 \\
\hline 18- Propaganda Realista & 1,1 & 3,1 & 1,9 & 1,9 & 1,9 & 4,6 & 5,4 & 14,9 & 21,5 & 23,4 & 20,3 & 100 \\
\hline 19-Intenção de comp. & - & 0,4 & 1,5 & 1,9 & 0,4 & 1,9 & 3,8 & 11,1 & 28,0 & 25,3 & 25,7 & 100 \\
\hline
\end{tabular}

\section{Tabela 4: Eficácia global da propaganda.}

Fonte: Elaborado pelos autores (2010)

A avaliação da percepção de risco sobre o produto apresentou concentração média de $57,8 \%$ da população com notas entre 0 e 2 . Entre 0 e 3 esta média é de 73,1\%, portanto, a propaganda via Realidade Aumentada analisada neste trabalho apresentou baixa avaliação de risco para o produto apresentado, uma vez que proporciona ao entrevistado a oportunidade de se ver usando o objeto, Tabela 5.

\begin{tabular}{|c|c|c|c|c|c|c|c|c|c|c|c|c|}
\hline Variáveis/ Grau & $\mathbf{0}$ & $\mathbf{1}$ & $\mathbf{2}$ & $\mathbf{3}$ & $\mathbf{4}$ & $\mathbf{5}$ & $\mathbf{6}$ & $\mathbf{7}$ & $\mathbf{8}$ & $\mathbf{9}$ & $\mathbf{1 0}$ & $\%$ \\
\hline Escolha errada & 18,0 & 24,9 & 22,2 & 15,7 & 6,9 & 7,3 & 2,7 &, 0 & 1,1 &, 8 &, 4 & 100 \\
\hline Arriscada & 14,2 & 19,9 & 23,4 & 17,2 & 6,9 & 10,0 & 2,3 & 2,3 & 2,3 & - & 1,5 & 100 \\
\hline Insatisfeito & 13,4 & 19,9 & 21,1 & 14,6 & 10,0 & 9,6 & 2,7 & 2,3 & 4,2 &, 4 & 1,9 & 100 \\
\hline N.atend.expect & 13,4 & 17,6 & 23,0 & 13,8 & 8,8 & 10,0 & 3,8 & 1,9 & 3,4 &, 8 & 3,4 & 100 \\
\hline
\end{tabular}

Tabela 5: Risco da compra do produto.

Fonte: Elaborado pelos autores (2010)

\subsection{Análise do Modelo Estrutural}

O modelo teórico proposto, que procura avaliar a influência da resposta afetiva, do entendimento e percepção de risco em relação à propaganda via Realidade Aumentada, foi avaliado 
pelo método de modelagem de equações estruturais com o uso da técnica PLS -Partial Least Square, por meio do software SmartPLS. Para constatar a validação do constructo criado, foi realizada análise confirmatória utilizando os critérios de: coeficiente de cada Path, Alfa de Cronbach, validade convergente e a variância extraída (AVE) como se pode observar no Tabela 6. Segundo Chin (1998) os padrões aceitos na literatura para confirmação estatística dos indicadores são: cargas fatoriais acima de 0,7; confiabilidade acima de 0,7 ; variância explicada acima de 0,5.

O teste de validade convergente do modelo foi realizado com base na analise fatorial confirmatória, realizada para cada construto estudado, onde foram identificadas as cargas fatoriais de cada variável do construto, com o objetivo de eliminar do modelo as variáveis com cargas fatoriais abaixo de 0,7 .

O constructo que envolve as variáveis para resposta afetiva apresentou cargas fatoriais satisfatórias para cada variável, com exceção da variável inveja (0,30). Portanto, a variável "inveja” foi excluída do constructo resposta afetiva uma vez que ela também apresentou características de média e desvio padrão fora do padrão encontrados nas outras variáveis, o que indica percepção confusa. $\mathrm{O}$ alfa de Cronbach, que avalia a consistência interna ou confiabilidade do constructo (HAIR, 2005), do constructo "resposta afetiva" foi de 0,845 , um nível considerado muito bom para este tipo de teste.

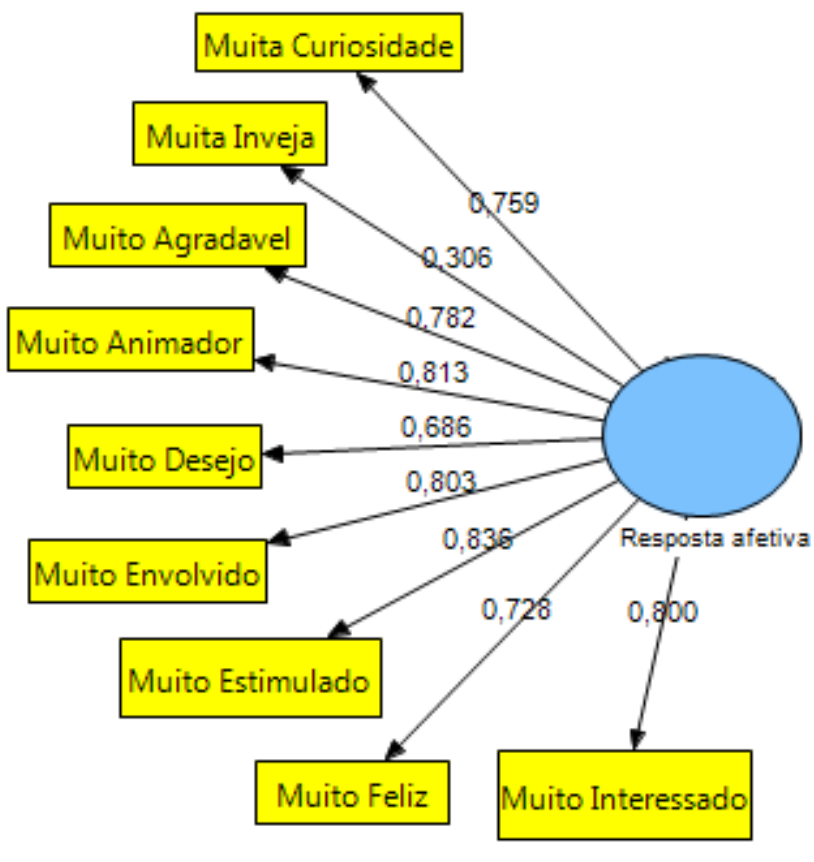

Figura 3: Constructo "Reposta afetiva".

Fonte: Elaborado pelos autores (2010) 
Para o constructo que envolve as variáveis de eficácia da propaganda também houve cargas fatorias satisfatórias para cada variável. Portanto, apesar de algumas variáveis ("aprender sobre o produto" e "entendimento sobre o produto") terem apresentado carga fatorial abaixo de 0,7 foi preferível mantê-las no constructo uma vez que os demais índices apresentaram-se satisfatórios. O alfa de Crobach do constructo "Eficácia" foi de 0,521, um nível considerado razoável para estudos exploratórios (HAIR, 2005).

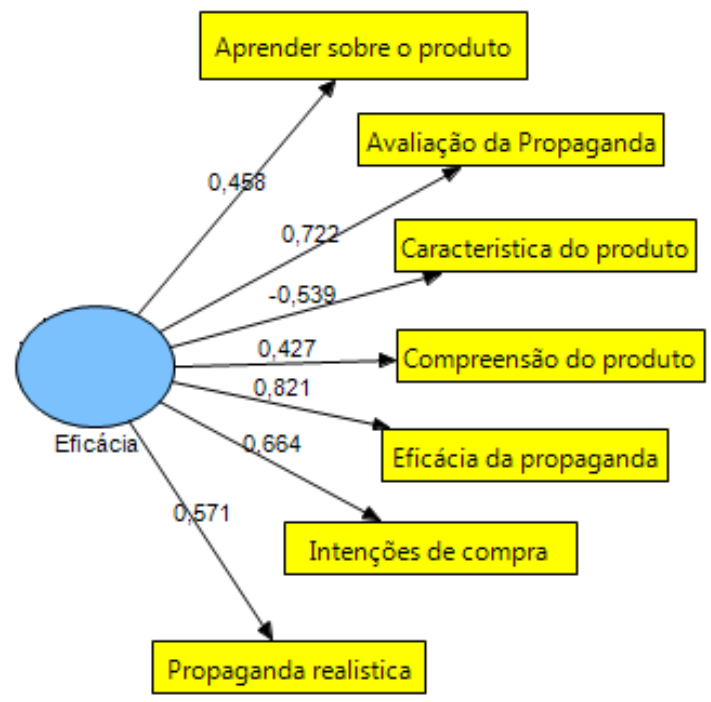

Figura 4: Constructo "Eficácia".

Fonte: Elaborado pelos autores (2010)

O constructo que envolve as variáveis de entendimento da propaganda também apresentou cargas fatorias satisfatórias para cada variável. Destacam-se as variáveis "propaganda confusa" e "significado ambíguo" com cargas fatoriais bastante elevadas indicando que de fato o entendimento da propaganda foi claro e direto. O alfa de Crobach também foi considerado muito bom $(0,844)$ para a confiabilidade do constructo.

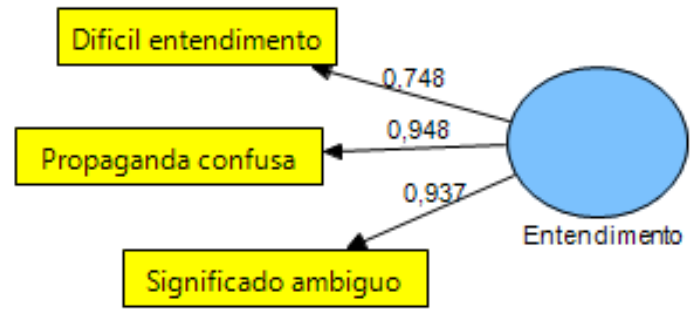

Figura 5: Constructo "Entendimento".

Fonte: Elaborado pelos autores (2010) 
Para o constructo da percepção de risco propaganda, observou-se também cargas fatorias bastante satisfatórias para cada variável. O alfa de Crobach de 0,851 valida bem a confiabilidade deste constructo.

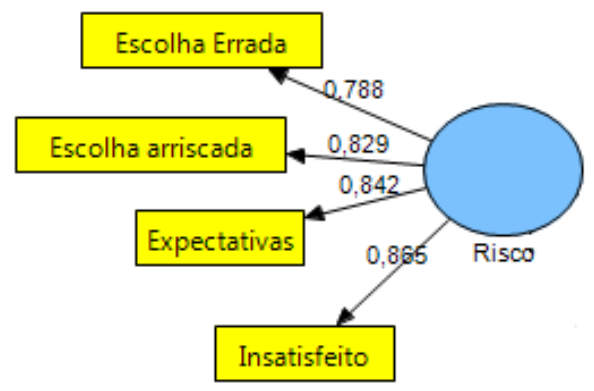

Figura 6: Constructo "Risco".

Fonte: Elaborado pelos autores (2010)

Após a verificação da validade convergente, foram identificados os resultados gerais do modelo, que serviram de base para verificação da validade discriminante.

\begin{tabular}{|c|c|c|c|c|}
\hline Variáveis & AVE & Composite Reliability & $\mathbf{R}^{\mathbf{2}}$ & Comunalidade \\
\hline Eficácia & 0,378 & 0,691 & 0,454 & 0,378 \\
\hline Entendimento & 0,779 & 0,913 & 0,000 & 0,779 \\
\hline Risco & 0,692 & 0,900 & 0,210 & 0,691 \\
\hline $\begin{array}{c}\text { Resposta } \\
\text { Afetiva }\end{array}$ & 0,606 & 0,912 & 0,000 & 0,548 \\
\hline
\end{tabular}

Tabela 6. Índice de desempenho do constructo.

Fonte: Elaborado pelos autores (2010)

A avaliação da validade discriminante teve por objetivo verificar se existem relações entre os constructos criados. Esta verificação é feita comparando a raiz quadrada da AVE com as correlações, de forma que a raiz da AVE deva ser sempre maior que as correlações. Abaixo a Tabela 7 mostra esta comparação, sendo a raiz da AVE a apresentada na coluna diagonal da matriz de correlações.

\begin{tabular}{|c|c|c|c|c|}
\hline AVE & Eficácia & Entendimento & Risco & Resposta Afetiva \\
\hline Eficácia & $\mathbf{0 , 6 1 5}$ & & & \\
\hline Entendimento & 0,394 & $\mathbf{0 , 8 8 3}$ & & \\
\hline Risco & $-0,440$ & $-0,261$ & $\mathbf{0 , 8 3 2}$ & \\
\hline Resposta Afetiva & 0,602 & 0,197 & $-0,445$ & $\mathbf{0 , 7 4 0}$ \\
\hline
\end{tabular}

Tabela 7. Índice de validade discriminante das variáveis latentes.

Fonte: Elaborado pelos autores (2010) 
Percebe-se que o modelo apresentou validade discriminante para todos os construtos, dando suporte à apresentação do modelo integrado.

$\mathrm{Na}$ visualização do modelo estrutural completo, percebe-se que a eficácia da propaganda via RA recebe, por ordem de significância, influência dos construtos: Resposta Afetiva (0,481); Entendimento $(0,259)$ e Risco (-0159). A confirmação destes dados é feita multiplicando os coeficientes Path $(\beta)$ pela correlação entre os constructos, obtendo-se Rsquare $\left(R^{2}\right)$, que indica a contribuição percentual de cada constructo para explicação da eficiência da propaganda.

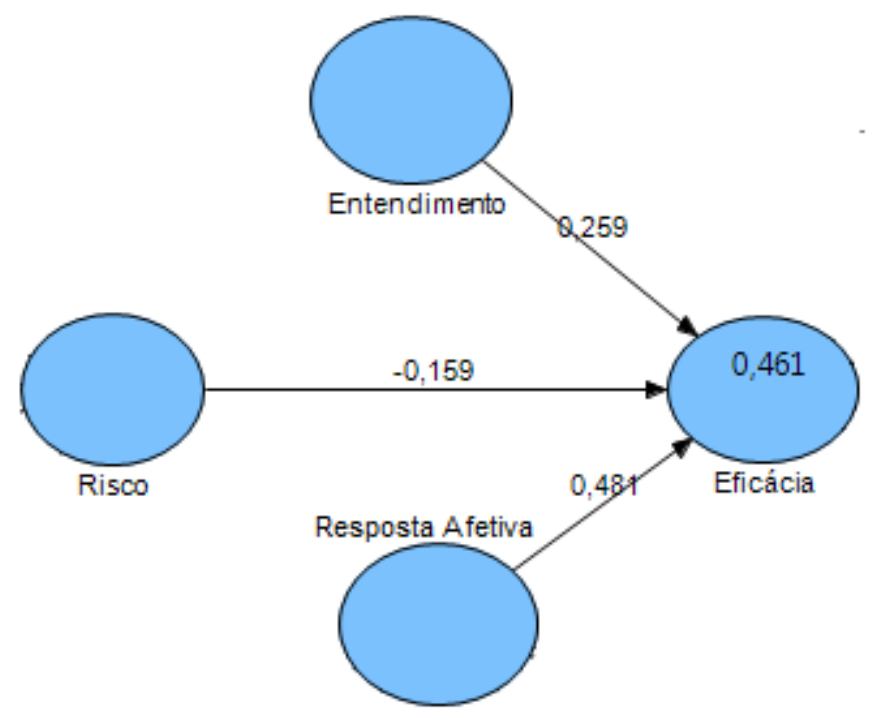

Figura 7: Constructo do Modelo Teórico. Fonte: Elaborado pelos autores (2010)

Pode-se observar, portanto, que 46,1\% da eficácia da propaganda é explicada pelo constructo que envolve: resposta afetiva, entendimento da propaganda e percepção de risco. A Tabela 8 também mostra a contribuição individual de cada constructo, a saber, entendimento (10,2\%), Risco (7,0\%) e Resposta afetiva $(29,0 \%)$.

A partir destes resultados pode-se inferir que apesar de os índices significativos de correlação ficando abaixo de 0,5 , o poder de explicação do modelo estrutural obteve um grau satisfatório, uma vez que o modelo contou com apenas três constructos preditivos (CHIN, 1998).

\begin{tabular}{|c|c|c|c|}
\hline Variáveis & $\boldsymbol{B}$ & $\mathbf{r}$ & $\mathbf{R}^{\mathbf{2}}$ (em \%) \\
\hline Entendimento & 0,259 & 0,394 & $10,2 \%$ \\
\hline Risco & $-0,159$ & $-0,440$ & $7,0 \%$ \\
\hline Resposta Afetiva & 0,481 & 0,602 & $29,0 \%$ \\
\hline
\end{tabular}

Tabela 8: $\mathbf{R}^{\mathbf{2}}$ dos antecedentes do constructo Eficácia.

Fonte: Elaborado pelos autores (2010) 
É possível observar uma importante contribuição do constructo "Resposta Afetiva" na avaliação da eficácia da propaganda via RA, indicando que a propaganda via Realidade Aumentada despertou o emocional dos entrevistados e isto foi bastante positivo na avaliação de eficácia da propaganda. A participação do entendimento da propaganda também foi significativo na explicação da eficácia da propaganda, o que indica o fato da utilização de RA em propaganda trazer um bom nível informacional ao cliente. O nível negativo do coeficiente $\square \square$ da percepção de risco de compra do produto indica uma relação antagônica entre o risco e a eficácia, onde os entrevistados ao avaliarem a propaganda como eficaz também perceberam um baixo nível de risco oferecido pelo produto.

Objetivando analisar se o modelo apresentado está ajustado à amostra utilizada, fez-se uso do método bootstraping. Trata-se de um método com amplo poder computacional em que repetidas subamostras são retiradas da base de dados original e calculados os parâmetros de interesse. Para tanto, definiu-se o cálculo para 200 sub-amostras, cujos resultados são apresentados na Tabela 9:

\begin{tabular}{|c|c|c|c|c|}
\hline Amostra original & $\begin{array}{c}\text { Média } \\
\text { amostras }\end{array}$ & (STDEV) & $\begin{array}{c}\text { Stand } \\
\text { Erro }\end{array}$ & Teste T \\
\hline Entendimento -> Eficácia & 0,2586 & 0,2548 & 0,0521 & 4,9613 \\
\hline Risco -> Eficácia & -01586 & 0,0656 & 0,0656 & 2,4163 \\
\hline $\begin{array}{c}\text { Resposta Afetiva -> } \\
\text { Eficácia }\end{array}$ & 0,4806 & 0,062 & 0,062 & 7,7546 \\
\hline
\end{tabular}

Tabela 9: Índices do método Bootstraping.

Fonte: Elaboração dos autores (2010)

Os resultados obtidos pelo método bootstraping mostram que a média obtida nas 200 subamostras, para cada relação entre os construtos são próximas da média da amostra original. Assim, com base nos resultados obtidos pelo modelo estrutural, faz-se necessário apontar o teste de hipóteses. Um parâmetro observável é a estatística T, com predominância de valores superiores a 1,96 (HAIR, 2005). Pelo teste T, todas as relações se confirmaram estatisticamente no modelo.

Desta forma, a hipótese H1: $O$ entendimento que o indivíduo obteve da propaganda exerce influência positiva na avaliação da eficácia da propaganda com Realidade Aumentada, foi confirmada pelo índice do teste $\mathrm{T}$ (4,9613), tendo um coeficiente path positivo de $(0,259)$. A confirmação desta hipótese reforça a idéia de que a propaganda com Realidade Aumentada é bem compreendida pelos consumidores e comprova a indicação feita pelo modelo estrutural de haver uma relação positiva do entendimento com a eficácia da propaganda.

$\mathrm{O}$ coeficiente Path relacionado à hipótese H2: O risco percebido na propaganda exerce influência negativa na avaliação da eficácia da propaganda com Realidade Aumentada foi negativo (-

Revista de Administração e Inovação, São Paulo, v. 10, n.3, p.09-36, jul./set. 2013. 
0,159). Isto confirma as expectativas da hipótese formulada, com apoio da confirmação do teste $\mathrm{T}$ $(2,4165)$, o que demonstra a relação negativa entre os o risco percebido e a eficácia da propaganda. Portanto, a confirmação da hipótese H2 indicada no modelo estrutural também confirma as estatísticas descritivas que mostraram um baixo de risco percebido em relação ao produto com o uso da Realidade Aumentada.

A confirmação hipótese H3: A resposta afetiva do indivíduo durante a propaganda exerce influência positiva na avaliação da eficácia da propaganda com Realidade Aumentada, se deu por meio do teste $\mathrm{T}(7,7546)$, demonstrando uma forte relação entre a resposta afetiva com a eficácia da propaganda. Uma vez que o coeficiente Path foi significativamente positivo $(0,481)$ o modelo conceitual foi também confirmado como correto ao afirmar sobre a influência da resposta afetiva sobre a eficácia da propaganda.

Desta forma, o modelo estrutural criado apresentou-se como eficiente em sua tarefa de determinar os fatores que possuem influencia na explicação da determinação da eficácia de uma propaganda usando a Realidade Aumentada.

\section{CONCLUSÕES}

Dada a crescente utilização de recursos tecnológicos na forma de mídia interativa, este trabalho procurou explorar os efeitos da resposta afetiva, entendimento e risco de compra em na eficácia da propaganda com Realidade Aumentada, uma vez que este tipo de tecnologia vem sendo cada vez mais utilizado como forma de atrair os consumidores. Desta forma, aspectos importantes para um melhor entendimento dos impactos do uso da tecnologia da Realidade Aumentada em mídia interativa bem como os fatores determinantes de sua eficácia foram observados.

O modelo teórico utilizado foi baseado em três constructos, entendimento, risco e resposta afetiva, que procuraram medir as principais atitudes e intenções do consumidor (BLACKWELL, MINIARD; ENGEL, 2005) em relação à eficácia de uma propaganda usando a tecnologia da Realidade Aumentada. Foram validadas estatisticamente todas as relações propostas nas hipóteses de pesquisa, revelando que de fato as interações entre os constructos afetam significativamente a eficácia da propaganda.

Revista de Administração e Inovação, São Paulo, v. 10, n.3, p.09-36, jul./set. 2013. 


\begin{tabular}{|c|c|c|}
\hline Modelo Teórico Proposto: Hipóteses & Teste T & $\begin{array}{c}\text { Resultado: } \\
\text { Modelo Final }\end{array}$ \\
\hline $\begin{array}{l}\text { Hipótese H1: O entendimento que o indivíduo obteve } \\
\text { da propaganda exerce influência positiva na avaliação } \\
\text { da eficácia da propaganda com Realidade Aumentada. }\end{array}$ & 4,9613 & $\begin{array}{c}\text { Confirmada a } \\
\text { influência }\end{array}$ \\
\hline $\begin{array}{l}\text { Hipótese H2: O risco percebido na propaganda exerce } \\
\text { influência negativa na avaliação da eficácia da } \\
\text { propaganda com Realidade Aumentada. }\end{array}$ & 2,4163 & $\begin{array}{c}\text { Confirmada a } \\
\text { influência }\end{array}$ \\
\hline $\begin{array}{l}\text { Hipótese H3: A resposta afetiva do indivíduo durante a } \\
\text { propaganda exerce influência positiva na avaliação da } \\
\text { eficácia da propaganda com Realidade Aumentada. }\end{array}$ & 7,7546 & $\begin{array}{c}\text { Confirmada a } \\
\text { influência }\end{array}$ \\
\hline
\end{tabular}

Tabela 10: Resumo das conclusões.

Fonte: Elaboração dos autores (2010)

Os pressupostos teóricos que serviram de base para a construção do modelo utilizado quanto ao constructo "entendimento", ao afirmarem sua influência positiva sobre a eficácia da propaganda (PAVLOU; STEWART, 2000), foram confirmados por meio da hipótese $H 1$, ou seja, existe um bom nível de entendimento da propaganda com Realidade Aumentada e este contribui significativamente para uma melhor eficácia deste tipo de propaganda.

Com relação ao conceito do risco de compra percebido (SOLOMON, 1998), este apresentou uma relação antagônica em relação à eficácia, confirmando a hipótese $H 2$, de forma que a experiência com a Realidade Aumentada é capaz reduzir os riscos percebidos em relação ao produto.

A hipótese H3, baseada nas conclusões de Martindable (1981) e Denis (2001), também confirmou uma forte influência da resposta afetiva na eficácia da propaganda com Realidade Aumentada. Ainda, destacam-se os altos escores atribuídos às variáveis do constructo "resposta afetiva" juntamente com o alto coeficiente de explicação no modelo estrutural, destacando o importante impacto emotivo que a Realidade Aumentada é capaz de causar.

A observação das estatísticas descritivas de cada constructo também foi importante ao revelar uma importante concentração de respostas positivas aos questionários em relação aos constructos "resposta afetiva", "entendimento" e "eficácia" e respostas negativas em relação ao constructo "risco".

Estas constatações reforçam o trabalho de Pavlou e Stewart, (2000) sobre melhores desempenhos em relação à eficácia de anúncios usando técnicas de mídia interativa e de fato contribuem teoricamente para o campo do entendimento do comportamento do consumidor diante de ações mercadológicas cada vez mais impactantes.

Revista de Administração e Inovação, São Paulo, v. 10, n.3, p.09-36, jul./set. 2013. 
Portanto, como implicações gerenciais, esta pesquisa aponta para o fato de que uso da tecnologia da Realidade Aumentada, e seu impacto positivo na resposta afetiva do consumidor, tornam este tipo de mídia ainda mais importante para empresas que buscam despertar este tipo de resposta de seus clientes. Como o risco de compra do produto se apresentou baixo diante deste tipo de propaganda, a Realidade Aumentada também se apresenta como uma forma de diminuir as barreiras entre a empresa e o seu mercado alvo por meio desta interação virtual. Assim, este trabalho contribui para o desenvolvimento de uma melhor compreensão das ações publicitárias que envolvem tecnologias avançadas e a interatividade com o consumidor, capazes de modificar o processo de comunicação de produtos e marcas.

\subsection{Limitações de Pesquisa e Sugestões para Estudos Futuros}

Quanto às limitações deste trabalho, deve-se observar que se tratou de uma pesquisa não intencional quanto à classificação do perfil dos respondentes, de forma que aspectos específicos dos entrevistados como gênero ou renda não foram observados.

Apesar do rigor metodológico, esta pesquisa apresenta dados levantados em um único período e para um tipo apenas de propaganda, de forma que não foi possível observar variações que podem ocorrer com outras formas de mídia interativa que usam a Realidade Aumentada.

Novas pesquisam, portanto, podem explorar o uso da Realidade Aumentada entre diferentes grupos focais e também pesquisar outros aspectos resultantes do uso desta tecnologia no impacto das vendas entre outros. A utilização de novos constructos para medir outros aspectos do comportamento do consumidor também é sugerida juntamente com pesquisas focadas na mensuração do poder de influência da R.A na efetivação da compra, para que se tenha uma visão mais ampla ainda a respeito das características da propaganda via Realidade Aumentada.

\section{REFERÊNCIAS}

ANDERSON, J. C. GERBING, D. W. Structural equation modeling in practice: A review and recommended two-step approach. Psychological Bulletin, 103 (3), 411-423. 1988.

AZUMA, R. T. Tracking Requirements for Augmented Reality. Communications of the ACM, 36(7):50-51, July, 1993.

Revista de Administração e Inovação, São Paulo, v. 10, n.3, p.09-36, jul./set. 2013. 
. Recent Advances in Augmented Reality. IEEE Computer Graphics and

Applications, v .21, n. 6, p. 34-47, 2001. Retreived November 14, 2007. Disponível

em: 〈http://www.cs.unc.edu/ azuma/cga2001.pdf>. Acesso: 20 mai 2011.

BATRA, Rajeev.; RAY, Michael L. Affective responses mediating acceptance of advertising. Journal of Consumer Research. v. 13, n. 2, p. 234-249, sep, 1986

BHAT, S, T.; LEIGH, W.;WARDLOW, L. The Effect of Consumer Prejudices on Ad. Journal of Advertising. V. 27. P.9-28.1998

BELELI, Iara. Corpo e identidade na propaganda. Revista Estudos Feministas, Universidade de Santa Catarina, Rio de Janeiro, 15(1): janeiro-abril/2007 Disponível em: <http://redalyc.uaemex.mx/pdf/381/38115112.pdf>. Acesso em: 20 dez 2010.

BRUNER, G. C.; HENSEL, P. J.; JAMES, Karen E. Marketing Scales Handbook: a compilation of multi-item measures for consumer behavior \& advertising, v. 4. Chicago: Thomson, 2005.

CUTLER, B. "The Fifth Medium," American Demographics, V.12, 24-29. 1990.

DEAN, D, H.; BISWAS, A. Third party Organization Endorsement of Products: An advertising Cue Affecting Consumer Prepurchase Evaluation of Goods and Services. Journal of Advertising. Vol. 30, P.41-57.2001

DENIS, C. Introduction to Psychology Gateways to Mind and Behavior. 9th Ed. California: Thomas Learning Inc. 2001

DURLACH, N. I.; MAVOR, A. S. Virtual Reality: Scientific and Technological Challenges. (Report of the Committee on Virtual Reality Research and Development to the National Research Council) National Academy Press, 1995.

ENGEL, G.; BLACKWELL, R. \& MINARD, P. Consumer Behavior, 8 ed. Fort Worth, Irwin, 1995.

EWING, Michael; NAPOLI, Julie; DU PLESSIS, Erik. Factors Affecting In-Market Recall of

Food Product Advertising. Journal of Advertising Research, 1999, p. 29-38

FILIPPO, D.; ENDLER, M.; FUKS, H. Colaboração Móvel com Realidade Aumentada. Rio de Janeiro, 2005. Dissertação de graduação, Ciência da Computação, Pontifícia Universidade Católica do Rio De Janeiro.

FERRARI, B. Realidade Aumentada: o mundo visto por outra dimensão. Revista Época Online,7jul.2009.Disponível em:<http://revistaepoca.globo.com/Revista/Epoca/0,EMI8093415259,00.html>. Acesso em: 07 de Fev. 2009.

FORNELL, C.; LARCKER, D. Evaluating Structural Equation Models with Unobservable Variables ad Measurement Error. Journal of Management, Vol 18 P.39-50. 1981.

GREENE, W. F. What Drives Commercial Liking? An exploration of entertainment versus communication. Journal of Advertising Research, 1992, p. 65-68.

Revista de Administração e Inovação, São Paulo, v. 10, n.3, p.09-36, jul./set. 2013. 
GRENCHO, Pedro Miguel Alvito. Comunicação em Serviços Públicos: O Impacto Percebido da Publicidade na Alteração de Comportamentos do Cidadão. Dissertação(Mestrado) Universidade Técnica de Lisboa, Instituto Superior de Economia e Gestão. Lisboa 2010. Disponívelem:http://www.repository.utl.pt/bitstream/10400.5/1849/1/Mestrado\%20Pedro\%20Alvito.p df> Acesso em: 5 fev 2011.

HAIR, J. F.; ANDERSON, R. E.; TATHAM, R. L.; BLACK, W. C. Análise Multivariada de Dados. 5.ed. São Paulo: Bookman, 2005.

HALEY, R. I.; BALDINGER, A. L. The ARF copy research validity project._Journal of Advertising Research, 31, 11-31. 1991.

HAVLENA, Willian J.; HOLBROOK, Morris B. The varieties of consumption experience: comparing two typologies of emotion in consumer behavior. Journal of Consumer Reseach. v. 13, p. 394-404, 1986.

HOFFMAN, D, L.; NOVAK, P. "Marketing in Computer-Mediated Environments: Conceptual Foundations," Journal of Marketing, V.60 (July), 50-68. 1996.

JACOBY, J.; SZYBILLO, G. J.; BUSATO-SCHACH, J.Information Acquisition Behavior in Brand Choice Situations. Journal ofConsumer Research, v.3, p. 209 - 216, march, 1977.

JORESKOG, K.; SORBOM, D. LISREL 8: Structural equation modeling with Simplis command language. Chicago, IL: Scientific Software International. 1993.

KANCHERLA, A. R., ROLlAND, J. P., WRIGHT, D. L.;BURDEA, G. A Novel Virtual Reality Tool for Teaching Dynamic 3D Anatomy. Nice, France, 3-6, 163-169. April 1995

KIRNER, C. e SISCOUTTO, R. A. Realidade Virtual e Aumentada: Conceitos, Projeto e Aplicações. Petrópolis: SBC - Sociedade Brasileira de Computação, Porto Alegre, 2007.

LEMOS, A. Mídia Locativa e Territórios Informacionais. In: Anais do COMPÓS, Curitiba, 2007.

LIKERT, Rensis. A Technique for the Measurement of Attitudes. Archives of Psychology , n. 140, p. $1-55,1932$.

MAlhotrA, N. K. Pesquisa de Marketing: Uma Orientação Aplicada. 4. ed. Porto Alegre: Bookman, 2006.

McQUARRIE, E.; MICK, D. G.; Visual Rethoric in Advertising: Text Interpretative, Experimental, and Reader Response Analysis. Journal of Consumer Research. V.26 P.37-54. 1999

MANO, Haim; OLIVER, Richard L. Assessing the dimenssionality and structure of the consuption experience: evaluation, feeling, and satisfaction. Journal of Consumer Research. V. 20, n.3, p. 451466, 1993.

MARTINDALE, C. Personality, situation, and creativity. In: Glover, J.A., Ronning, R.R. and Reynolds, C.R., Editors, 1989. Handbook of creativity, Plenum, New York, pp. 211-232. 1989

Revista de Administração e Inovação, São Paulo, v. 10, n.3, p.09-36, jul./set. 2013. 
MERIGO, C. Doritos Sweet Chili terá código de Realidade Aumentada nas embalagens. Disponível em: <http://www.brainstorm9.com.br/2009/03/31/doritos-sweet-chili-tera-codigo-derealidade-aumentada-nas-embalagens/>. Acesso em: 12 fev. 2010.

MOREAU, P.; MARKMAN, B.; LEHMANN, R. What is It? Categorization Flexibility and consumers Response to Really New Products. Journal of Consumer Research. V.4 P.489-498. 2004.

MURPHY, William; TANG, Sidney. Continuous Likability Measurement. Marketing

Research, v. 10, n. 2, p. 28-35, 1998.

NELSON, P. Information and consumer behavior. Journal of Political Economy, vol. 78, n.2, March/April, p. 311-329. 1970

NOVITSKI, B. Virtual Reality for Architects, Journal of Architecture, October 1994.

OLOUFA, A. Modeling and Simulation of Construction Operations. Automation in Construction, V.1(4), 351-359. 1993.

OHMAR TACLA. Realidade Aumentada é a moda, na Publicidade Disponível em: http://blogs.abril.com.br/blogdojj/2009/10/realidade-aumentada-moda-na-publicidade.html. Acesso em 10 out 2009.

PORT, O. "Customers Move Into the Driver's Seat," Business Week, (October 4), pp. 103-106. 1999.

PAVLOU, A,P. STEWART, D, W. Measuring the Effects and Effectiveness of Interactive Advertising: A Research Agenda. Journal of Interactive Marketing. Vol1. N.1. October. 2000.

RICHINS, Marsha L. Measuring Emotions inthe Consumption Experience. Journal of Consumer Research, v. 24, p. 127-146, 1997.

SANTOS F, C. O. Estudo e Aplicação da Tecnologia de Realidade Aumentada. Recife, 2005. Dissertação de graduação, Engenharia da Computação, Universidade de Pernambuco.

SIMONSON, I.; CARMON, Z.; DHAR, R.; DROLET, A.; NOWLIS, S. M.

Consumer research: In search of identity. Annual Review of Psychology, V. 52, P.249-275.2001.

SISCOUTTO, R; COSTA, R. Realidade Virtual e Aumentada: Uma Abordagem Tecnológica. X Symposium on Virtual and Augmented Reality, João Pessoa, mai., 2008.

SHETH, Jagdish; MITTAL, Banwari; NEWMAN, Bruce I. Comportamento do cliente: indo além do comportamento do consumidor. São Paulo: Atlas, 2001.

TORI, R.; KIRNER, C.; SISCOUTTO, R. Fundamentos e Tecnologia de Realidade Virtual e Aumentada. VIII Symposium on VirtualReality, Belém, mai., 2006.

WESTBROOK, Robert A.; OLIVER, Richar L. The dimensionality of consumtion emotion patterns and consumer satisfaction. Journal of Consumer Research. v. 18, p. 84-91, june,1991. 
YIN, R. K. Estudo de caso: planejamento e métodos. 3. ed. Porto Alegre: Bookman, 2005.

ZHOU Feng: Trends in augmented reality tracking, interaction and display: A review of ten years of ISMAR. 7th IEEE/ACM International Symposium on Mixed and Augmented Reality. Cambridge, UK September 15-September 18 ISBN: 978-1-4244-2840-3, 2008.

\begin{abstract}
The Virtual Reality, technique that allows the interaction between humans and computers, has been improved and advanced to the so called Augmented Reality (AR), which allows the interaction "userenvironment" more efficient and rich. This research aims to understand how consumers assess the effectiveness of the use of Augmented Reality technology the Internet based on the constructs of risk perception of consumers regarding the product, affective response perceived during the experience and general understanding of the advertising. Was used as a theoretical base, knowledge regarding the uses of augmented reality, and research involving the four pillars of the theoretical study: risk perception, understanding, feelings and effectiveness of advertising. We performed an exploratory research, mainly quantitative, with questionnaires to 261 respondents, which were approached in a nonprobabilistic. The results showed that using the technology of augmented reality, the understanding of advertising has a positive and statistically significant relationship with the efficacy of the advertising, just as the sensations are also positively related to the effectiveness of the advertising. However, the perceived risk has a negative relationship with effectiveness, confirming the hypothesis tested by this research and existing literature.
\end{abstract}

Keywords: Innovation; Advertising; Augmented Reality. 